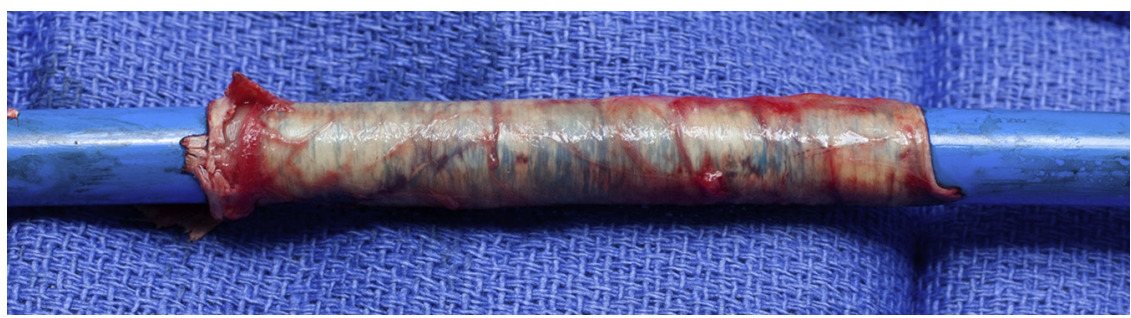

FIGURE 2. Close-up view of external iliac artery avulsion on sheath. The specimen represents the entire external iliac artery.

qualifiers such as major, minor, or presence of percutaneous closure device failure.

\section{References}

1. Kappetein AP, Head SJ, Genereux P, Piazza N, van Mieghem NM, Blackstone EH, et al. Updated standardized endpoint definitions for transcatheter aortic valve implantation: the Valve Academic Research Consortium-2 consensus document. J Thorac Cardiovasc Surg. 2013;145:6-23.
2. Leon MB, Piazza N, Nikolsky E, Blackstone EH, Cutlip DE, Kappetein AP, et al. Standardized endpoint definitions for transcatheter aortic valve implantation clinical trials: a consensus report from the valve academic research consortium. J Am Coll Cardiol. 2011;57:253-69.

3. Smith CR, Leon MB, Mack MJ, Miller DC, Moses JW, Svensson LG, et al. Transcatheter versus surgical aortic-valve replacement in high-risk patients. N Engl J Med. 2011;364:2187-98.

4. Adams DH, Poma JJ, Reardon MJ, Yakubov SJ, Coselli JS, Deeb GM, et al. Transcatheter aortic-valve replacement with a self-expanding prosthesis. $N$ Engl J Med. 2014;370:1790-8.

\title{
Thrombosis following mitral and tricuspid valve-in-valve replacement
}

\author{
Brian Whisenant, MD, ${ }^{\mathrm{a}}$ Kent Jones, MD, ${ }^{\mathrm{a}}$ Dylan Miller, MD, ${ }^{\mathrm{b}}$ Steven Horton, MD, ${ }^{\mathrm{a}}$ and \\ Edward Miner, MD, ${ }^{a}$ Salt Lake City, Utah
}

There is a growing and robust experience demonstrating the safety and efficacy of valve-in-valve (VIV) implantation in the aortic position. ${ }^{1}$ Mitral and tricuspid VIV implantation is also technically feasible with excellent acute outcomes., ${ }^{2,3}$ Sapien valve (Edwards LifeSciences, Irvine, Calif) thrombosis has been reported as a rare event following transcatheter aortic valve replacement (TAVR) in the setting of native valve aortic stenosis. ${ }^{4} \mathrm{We}$ describe 3 cases of Sapien valve thrombosis following

\footnotetext{
From the Intermountain Heart Institute ${ }^{\mathrm{a}}$ and Department of Pathology, ${ }^{\mathrm{b}}$ Intermountain Medical Center, Salt Lake City, Utah.

Disclosures: B.W. receives honoraria for speaking and proctoring from Edwards LifeSciences. K.J. receives honoraria for proctoring from Edwards LifeSciences. All other authors have nothing to disclose with regard to commercial support.

Received for publication Aug 31, 2014; revisions received Oct 3, 2014; accepted for publication Oct 10, 2014; available ahead of print Dec 2, 2014.

Address for reprints: Brian Whisenant, MD, Cardiology Research, Intermountain Medical Center, 5121 S Cottonwood St, Bldg 4, L6, Murray, UT 84107 (E-mail: brian.whisenant@imail.org).

J Thorac Cardiovasc Surg 2015;149:e26-9

$0022-5223 / \$ 36.00$

Copyright (c) 2015 by The American Association for Thoracic Surgery

http://dx.doi.org/10.1016/j.jtcvs.2014.10.075
}

successful mitral (2 cases) and tricuspid (1 case) VIV deployment and discuss the implications of these observations.

\section{CLINICAL SUMMARY}

The Intermountain Medical Center VIV experience includes 7 patients with failed mitral bioprostheses, 2 patients with repaired mitral valves utilizing mitral annuloplasty rings, and 2 patients with failed tricuspid bioprostheses. All transcatheter valves were successfully deployed and all patients were discharged from the hospital without significant adverse events. The immediate postprocedure mean transesophageal echocardiography (TEE) gradient across the Sapien valves was $<5 \mathrm{~mm} \mathrm{Hg}$ in all patients without more than trace valvular or paravalvular regurgitation. Three patients with valve thrombosis are highlighted in Table 1 and reviewed in detail below.

\section{Patient 1}

A 54-year-old man with a complex history of 2 prior sternotomies, including ascending aortic aneurysm as well 
TABLE 1. Intermountain Medical Center experience with Sapien valves deployed in the mitral and tricuspid positions

\begin{tabular}{|c|c|c|c|c|c|c|}
\hline Mitral patients & $\begin{array}{c}\text { Failed } \\
\text { bioprosthesis* }\end{array}$ & $\begin{array}{l}\text { True internal } \\
\text { diameter, } \mathbf{m m}\end{array}$ & $\begin{array}{c}\text { Regurgitant } \\
\text { or stenosis }\end{array}$ & Sapien & Access & $\begin{array}{l}\text { Antithrombotic } \\
\text { regimen at discharge }\end{array}$ \\
\hline $1 \dagger$ & 29 Mosaic & 24 & MR & $26 \mathrm{~S}$ & TA & Aspirin $81 \mathrm{mg}$ \\
\hline $2 \dagger$ & 31 Epic & 26.5 & MS & $26 \mathrm{~S}$ & $\mathrm{TA}$ & Clopidogrel $75 \mathrm{mg}$ \\
\hline 3 & 29 Hancock & 24 & MR & $26 \mathrm{~S}$ & TA & Aspirin $162 \mathrm{mg}$, clopidogrel $75 \mathrm{mg}$ \\
\hline 4 & 27 Perimount & 25 & MS & $26 \mathrm{~S}$ & $\mathrm{TF}$ & Aspirin $81 \mathrm{mg}$ \\
\hline 5 & 25 Hancock II & 20.5 & MR & $23 \mathrm{~S}$ & $\mathrm{TA}$ & Aspirin $81 \mathrm{mg}$, clopidogrel $75 \mathrm{mg}$ \\
\hline 6 & 31 Epic & 26.5 & MR & $26 \mathrm{XT}$ & $\mathrm{TF}$ & Warfarin \\
\hline 7 & 31 Mosaic & 26 & MR & $29 \mathrm{XT}$ & TA & Warfarin \\
\hline \multicolumn{7}{|l|}{ Tricuspid patients } \\
\hline $1 \dagger$ & 31 Mosaic & 26 & TR & $26 \mathrm{~S} \times 2 \ddagger$ & $\mathrm{TF}$ & Aspirin $81 \mathrm{mg}$, clopidogrel $75 \mathrm{mg}$ \\
\hline 2 & 33 Epic & 28.5 & TS & $29 \mathrm{XT}$ & $\mathrm{TF}$ & Warfarin \\
\hline \multicolumn{7}{|c|}{ Mitral annuloplasty ring patients } \\
\hline 1 & 28 Cosgrove & & MR & $26 \mathrm{~S}$ & TA & Aspirin $81 \mathrm{mg}$ \\
\hline 2 & 26 Cosgrove & & MS & $26 \mathrm{~S}$ & TA & Clopidogrel $75 \mathrm{mg}$ \\
\hline
\end{tabular}

$M R$, Mitral regurgitation; $T A$, transapical; $M S$, mitral stenosis; $T F$, transfemoral; $T R$, tricuspid regurgitation; $T S$, tricuspid stenosis. *Mosaic and Hancock: Medtronic Inc, Min-

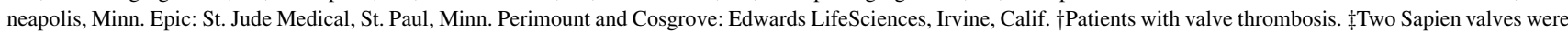
used given distal displacement of the first valve resulting in moderate residual tricuspid regurgitation.

as aortic and mitral valve replacements, presented with heart failure and was found to have severe stenosis of his $29 \mathrm{~mm}$ Mosaic mitral bioprosthesis (Medtronic, Minneapolis, Minn). A 26-mm Sapien valve was deployed within the stenotic Mosaic bioprosthesis and he was discharged with a prescription for $81 \mathrm{mg} /$ day aspirin. He presented 17 months later with progressive dyspnea. TEE revealed nodular densities fixed to the ventricular side of the Sapien valve and restricted Sapien leaflet motion associated with mitral stenosis (mean gradient $20 \mathrm{~mm} \mathrm{Hg}$ ) and moderate mitral regurgitation. The patient was taken to the operating room where thrombi affixed to the ventricular side of all 3 Sapien leaflets were identified. A mechanical prosthesis was implanted. Surgical pathology identified organized and acute thrombus adherent to the Sapien leaflets (Figure 1).

\section{Patient 2}

A 67-year-old man with a history of bypass surgery underwent orthotopic heart transplantation followed by 31-mm Epic mitral valve (St Jude Medical, St Paul, Minn) replacement. He did well for 6 years until developing severe mitral stenosis. A 26-mm Sapien valve was deployed within the failed Epic bioprosthesis and the patient was discharged with a prescription for $75 \mathrm{mg}$ clopidogrel daily. He returned 11 days later complaining of exertional dyspnea. TEE revealed an immobile mitral valve leaflet with a mean mitral valve gradient of $12 \mathrm{~mm} \mathrm{Hg}$. Warfarin was added to the clopidogrel regimen. A TEE repeated 3 weeks after initiating warfarin therapy demonstrated normal Sapien valve mobility. He presented 6 months later with recurrent dyspnea having discontinued warfarin and was again found
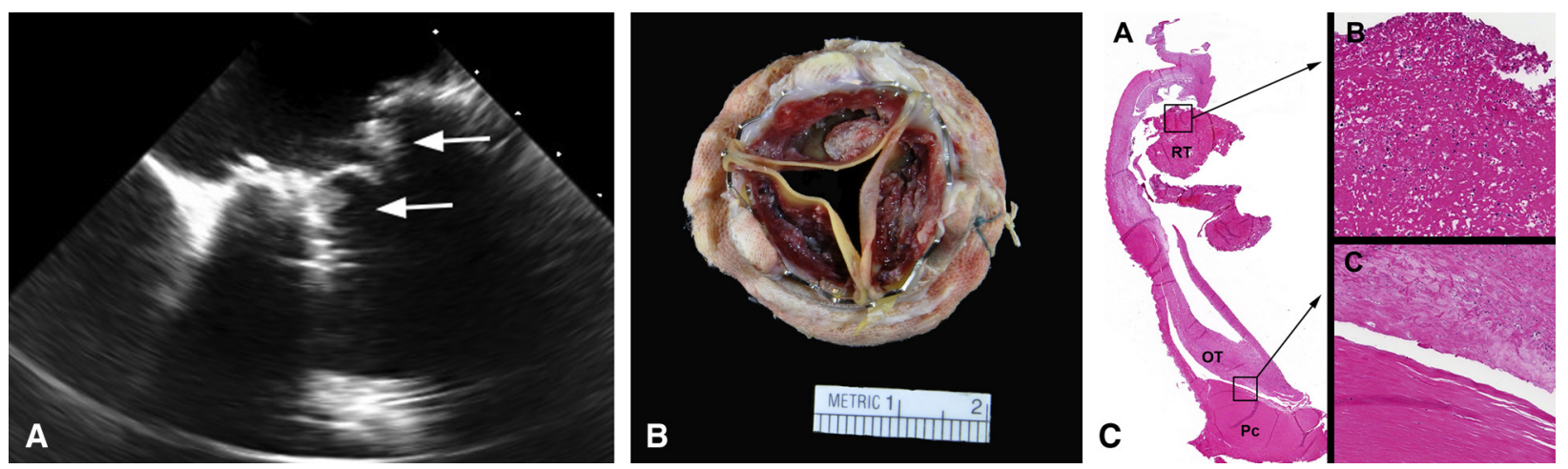

FIGURE 1. Patient 1. A, Transesophageal echocardiography demonstrating nodular thrombotic density (arrows). B, Thrombus adherent to the ventricular side of the Sapien (Edwards LifeSciences, Irvine, Calif) valve leaflets. C, Low magnification photomicrograph of Sapien valve leaflet showing the relationship of the pericardial $(P c)$ leaflet tissue, shallow overlying old organized thrombus $(O T)$, and more recent thrombus $(R T)$ in the cusp pocket. The base of the valve is oriented at the bottom of the image (hematoxylin and eosin stain $\times 10$ ). Panel B shows higher magnification of the recent thrombus component (hematoxylin and eosin stain $\times 100$ ). Panel $\mathrm{C}$ shows higher magnification of the organized thrombus component $($ top) and acellular dense collagenous pericardial leaflet tissue (hematoxylin and eosin stain $\times 100$ ). 


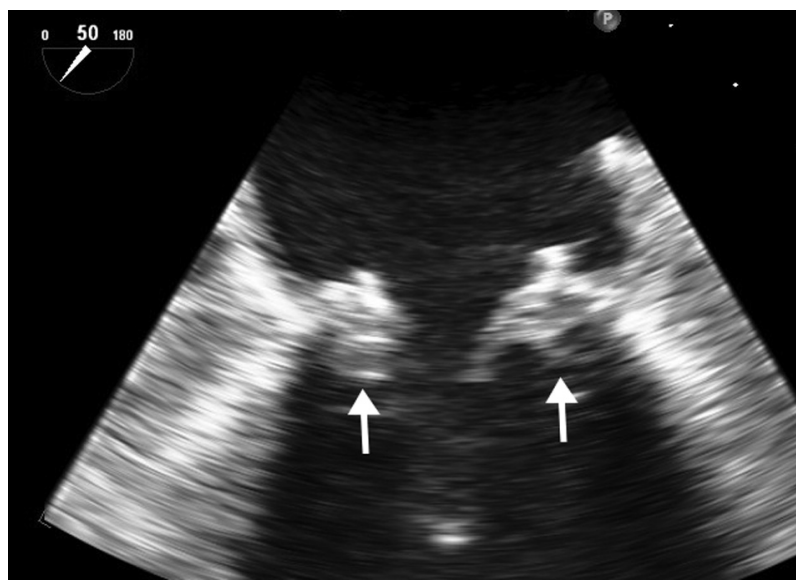

FIGURE 2. Patient 2. Transesophageal echocardiography showing nodular thrombotic densities (arrows).

to have nodular densities adherent to the ventricular side of the Sapien leaflets with diminished leaflet mobility, a mean mitral valve gradient of $20 \mathrm{~mm} \mathrm{Hg}$, and mild-to-moderate mitral regurgitation (Figure 2). A TEE performed 4 weeks following the administration of warfarin revealed resolution of the nodular thrombus, associated mitral regurgitation, and mitral stenosis.

\section{Patient 3}

A 50-year-old woman with Ebstein anomaly underwent tricuspid valve replacement with a 31-mm Mosaic bioprosthesis. She was well for 1 year until she reported acute onset dyspnea and was found to have severe tricuspid regurgitation. A 26-mm Sapien valve was deployed within the tricuspid bioprosthesis. Moderate residual tricuspid insufficiency was noted and the valve was deemed to be excessively distal, toward the right ventricle. A second 26-mm Sapien valve was deployed more proximally with an excellent result. She was discharged with a prescription for aspirin and clopidogrel. A routine follow-up transthoracic echocardiogram 6 weeks later revealed a mean gradient of $10 \mathrm{~mm} \mathrm{Hg}$. A TEE revealed thrombus adherent to the ventricular aspect of 1 Sapien leaflet with diminished leaflet mobility and moderate tricuspid regurgitation. Warfarin therapy was initiated. Echocardiography has not yet been repeated.

\section{DISCUSSION}

Our 3 cases of valve thrombosis represent 3 of our 9 patients with stented bioprosthetic valves in either the mitral or tricuspid position. We have not observed Sapien valve thrombosis in our 18 patients with aortic VIV implants. The mechanisms underlying valve thrombosis are likely multifactorial and may include inadequate postprocedure anticoagulation, low atrial pressure valve opening, and constrained Sapien stent expansion or leaflet motion by the failed bioprosthetic stent frame. We did not test for hypercoagulability in these patients.
Both patients with mitral valve thrombosis were discharged with single-agent antiplatelet therapy. The 2014 American Heart Association/American College of Cardiology guideline for the management of patients with valvular heart disease ${ }^{5}$ suggests $75 \mathrm{mg} /$ day clopidogrel for 6 months after TAVR in addition to lifelong 75 to 100 $\mathrm{mg} /$ day aspirin. However, this guideline focuses on the risk of thromboembolism following TAVR and does not address transcatheter valve thrombosis.

Low atrial valve opening pressure is an attractive hypothesis to explain our observation of thrombosis. Edwards LifeSciences has performed in vitro hydrodynamic testing of Sapien XT valves implanted in calcified, explanted bioprosthetic valves with varying flow and pressure hydrodynamic conditions to simulate both the aortic and mitral positions. This testing was performed to facilitate European Union approval of a VIV indication. The results meet the minimum performance requirements for hydrodynamic performance and durability of mitral VIV procedures. (Data on file with Edwards LifeSciences and pending publication.) Our tricuspid patient received 2 Sapien valves. Sapien valve within Sapien valve procedures have been performed with excellent results and are not associated with diminished excursion or poor valve performance. ${ }^{6}$

The potential for valve thrombosis warrants increased awareness and surveillance. We failed to recognize the thrombotic etiology of his mitral stenosis in our first patient, having attributed this to pannus tissue growth. We initially failed to recognize the increased gradient of our tricuspid patient as valve thrombosis until we reexamined her with heightened awareness. In our experience, Sapien thrombosis presented with mixed stenosis and regurgitation. We did not appreciate mitral or tricuspid regurgitation during transthoracic color Doppler evaluation given acoustic shadowing. Increased diastolic inflow signals may represent either regurgitation or stenosis and warrant TEE interrogation of the Sapien valve.

The favorable hemodynamic profile and lack of paravalvular insufficiency may invite Sapien VIV implantation in patients with failed bioprosthetic valves, including younger patients who are anxious to avoid mechanical valve-associated chronic anticoagulation but will likely outlive a newly implanted bioprosthesis, as is the case in patients 1 and 3 above. If Sapien valves implanted within failed mitral and tricuspid bioprostheses are associated with an increased risk of thrombosis, the intended benefit of avoiding chronic anticoagulation may not be realized.

\section{CONCLUSIONS}

Additional research is indicated to clarify the long-term durability and optimal postprocedure management of mitral and tricuspid VIV replacement. Oral anticoagulation may be considered following mitral or tricuspid VIV implants pending further data. 


\section{References}

1. Bapat V, Attia R, Redwood S, Hancock J, Wilson K, Young C, et al. Use of transcatheter heart valves for a valve-in-valve implantation in patients with degenerated aortic bioprosthesis: technical considerations and results. J Thorac Cardiovasc Surg. 2012;144:1372-9; discussion 9-80.

2. Cheung AW, Gurvitch R, Ye J, Wood D, Lichtenstein SV, Thompson C, et al. Transcatheter transapical mitral valve-in-valve implantations for a failed bioprosthesis: a case series. J Thorac Cardiovasc Surg. 2011;141:711-5.

3. Hon JK, Cheung A, Ye J, Carere RG, Munt B, Josan K, et al. Transatrial transcatheter tricuspid valve-in-valve implantation of balloon expandable bioprosthesis. Ann Thorac Surg. 2010;90:1696-7.
4. Pergolini A, Pino PG, Zampi G, Polizzi V, Musumeci F. Thrombotic aortic restenosis after transapical SAPIEN valve implantation. J Cardiac Surg. 2014; 29:204-8.

5. Nishimura RA, Otto CM, Bonow RO, Carabello BA, Erwin JP 3rd, Guyton RA, et al 2014 AHA/ACC Guideline for the management of patients with valvular heart disease: a report of the American College of Cardiology/American Heart Association Task Force on Practice Guidelines. J Am Coll Cardiol. 2014;63:e57-185.

6. Giri J, Bortnick AE, Wallen T, Walsh E, Bannan A, Desai N, et al. Procedural and clinical outcomes of the valve-in-valve technique for severe aortic insufficiency after balloon-expandable transcatheter aortic valve replacement. Cath Cardiovasc Interv. 2012;80:139-47.

\title{
Successful repair of a variant of mitral arcade
}

\author{
Giuseppe Ferro, MD, ${ }^{\mathrm{a}}$ Sabrina D. Phillips, MD ${ }^{\mathrm{b}}$ Frank Cetta, Jr, MD, ${ }^{\mathrm{b}}$ and Rakesh M. Suri, MD, DPhil, ${ }^{\mathrm{a}}$ \\ Rochester, Minn
}

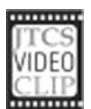

Video clip is available online.

Mitral arcade (MA) is a very rare mitral anomaly characterized by abnormal subvalvular apparatus development. The papillary muscles are usually directly attached to both leaflets. We present an unusual case in which the posterior mitral leaflet (PML) was solely affected, leading to tethering, malcoaptation, and regurgitation.

\section{CLINICAL SUMMARY}

A 17-year-old girl was seen at our clinic after a new diagnosis of a systolic cardiac murmur. She reported symptoms of fatigue but not dyspnea, palpitations, or chest pain. History was negative for rheumatic disease. Physical examination revealed a healthy-appearing young woman with a harsh $3 / 6$ holosystolic murmur at the apex, radiating toward the axilla. Chest radiography showed mild cardiac enlargement but was otherwise unremarkable. A transthoracic echocardiogram revealed a moderately thickened mitral valve with a central coaptation gap resulting from restricted PML motion. There was

\footnotetext{
From the Intermountain Heart Institute ${ }^{\mathrm{a}}$ and Department of Pathology, ${ }^{\mathrm{b}}$ Intermountain Medical Center, Salt Lake City, Utah.

Disclosures: Authors have nothing to disclose with regard to commercial support. Received for publication Oct 29, 2014; accepted for publication Nov 6, 2014; available ahead of print Dec 19, 2014.

Address for reprints: Rakesh M. Suri, MD, DPhil, Division of Cardiovascular

Surgery, 200 1st St SW, Rochester, MN 55905 (E-mail: Suri.Rakesh@mayo.edu). J Thorac Cardiovasc Surg 2015;149:e29-31

$0022-5223 / \$ 36.00$

Copyright (C) 2015 by The American Association for Thoracic Surgery

http://dx.doi.org/10.1016/j.jtcvs.2014.11.042
}

severe regurgitation, with a mean gradient of $8 \mathrm{~mm} \mathrm{Hg}$. The left heart chambers were severely enlarged. Calculated ejection fraction was $58 \%$. Surgical treatment with repair or replacement of the mitral valve was recommended.

Preoperative transesophageal echocardiography confirmed limited excursion of the PML, which created an eccentric regurgitation jet toward the dome of the left atrium. The PML chordae tendineae were foreshortened and thickened; the papillary muscles were closely spaced in the configuration of a partial arcadelike structure (Figure 1, A, and Video 1). During direct inspection at the time of surgery, the PML was small, thick, and severely tethered. Mobility was limited. The leaflet was delaminated with a sharp incision and completely detached from the annulus except for most extreme medial and lateral portions. An oval-shaped bovine pericardium patch was used to augment the PML surface and sutured circumferentially. The posteromedial commissure was then plicated to achieve better competence (Figure 2, $A-D$ ). The valve appeared to be functioning well, and saline solution testing revealed valve competence. A postprocedural echocardiogram showed bowing of the midportion of the neo-PML with the leading edge coaptation margin intact, revealing trivial regurgitation and mild stenosis (Figure 1, $B-D$, and Videos 2 and 3). The patient's postoperative course was uneventful, and she was released on postoperative day 6 .

\section{DISCUSSION}

MA is a very rare mitral anomaly. ${ }^{1,2}$ First described by Layman and Edwards ${ }^{1}$ in 1967, MA is characterized by abnormal subvalvular apparatus development. The papillary muscles are usually directly attached to both leaflets. When present, short and thick chords are typically distributed 